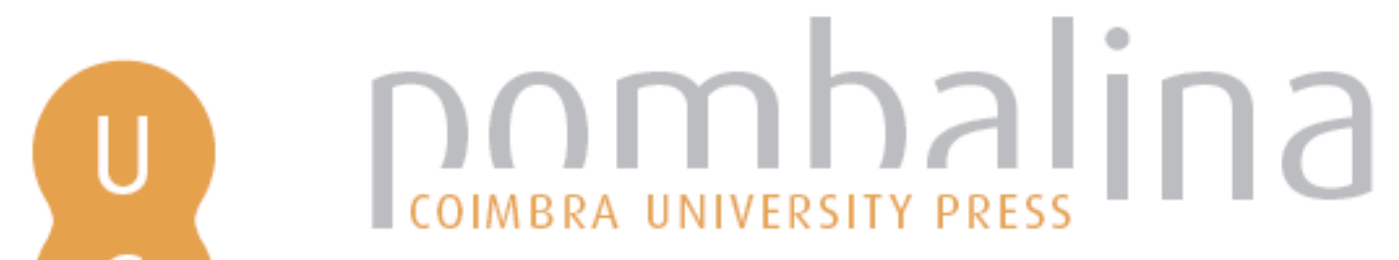

\title{
Lo mejor es el agua
}
Autor(es):
García Romero, Fernando
Publicado por: Imprensa da Universidade de Coimbra
URL persistente:
URI:http://hdl.handle.net/10316.2/45096
DOI:
DOI:https://doi.org/10.14195/978-989-26-1568-4_2

Accessed : $\quad$ 26-Apr-2023 14:23:01

A navegação consulta e descarregamento dos títulos inseridos nas Bibliotecas Digitais UC Digitalis, UC Pombalina e UC Impactum, pressupõem a aceitação plena e sem reservas dos Termos e Condições de Uso destas Bibliotecas Digitais, disponíveis em https://digitalis.uc.pt/pt-pt/termos.

Conforme exposto nos referidos Termos e Condições de Uso, o descarregamento de títulos de acesso restrito requer uma licença válida de autorização devendo o utilizador aceder ao(s) documento(s) a partir de um endereço de IP da instituição detentora da supramencionada licença.

Ao utilizador é apenas permitido o descarregamento para uso pessoal, pelo que o emprego do(s) título(s) descarregado(s) para outro fim, designadamente comercial, carece de autorização do respetivo autor ou editor da obra.

Na medida em que todas as obras da UC Digitalis se encontram protegidas pelo Código do Direito de Autor e Direitos Conexos e demais legislação aplicável, toda a cópia, parcial ou total, deste documento, nos casos em que é legalmente admitida, deverá conter ou fazer-se acompanhar por este aviso.

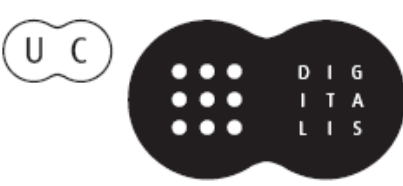




\section{O melhor é a água}

\section{Da antiguidade clássica aos}

nossos dias

José Luís Brandão \& Paula Barata Dias (coords.) 


\title{
LO MEJOR ES EL AGUA (The Best Is Water)
}

\author{
Fernando García Romero (fgarciar@filol.ucm.es) ${ }^{1}$ \\ Departamento de Filología Clásica \\ Universidad Complutense de Madrid \\ orcid.org/0000-0002-2543-1507
}

\begin{abstract}
Resumo - Desde hace dos mil doscientos años, a partir de que Aristófanes de Bizancio llevara a cabo su edición de Píndaro, los lectores del poeta tebano comenzamos nuestra lectura de su obra con una frase enigmática, cuya interpretación ha suscitado muchas

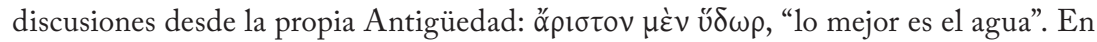
nuestro escrito comentamos las diferentes interpretaciones que, desde la Antigüedad, se han propuesto para explicar en qué sentido dice Píndaro que lo mejor es el agua, e intentamos situar tal afirmación dentro del contexto de la obra de Píndaro y, más en general, dentro del contexto de la lírica griega arcaica y clásica.

Palavras-chave - Píndaro, agua, valores supremos, cuatro elementos.
\end{abstract}

Abstract - Since Aristophanes of Byzantium produced his edition of Pindar's poems 2200 years ago, readers of the Theban poet have begun their study of his works with an enigmatic sentence whose interpretation has provoked much discussion since the age of Antiquity: ápı rent interpretations that have been proposed since Antiquity in order to explain the sense in which Pindar claims that water is best. We intend to situate this affirmation within the context of the Pindar's work and, in a more general way, within the context of archaic and classical Greek lyric poetry.

KEY-words - Pindar, water, supreme values, four elements.

La filología alejandrina, y en concreto Aristófanes de Bizancio, dividió la obra de Píndaro en 17 libros, dentro de los cuales los poemas se agrupaban según el género literario al que se adscribían. Como es sabido, Aristófanes colocó en primer lugar los epinicios, como piezas que consideraba las más características de la poesía pindárica. Los epinicios ocupaban los cuatro primeros libros, cada uno de los cuales recogía los poemas destinados a celebrar las victorias en cada uno de los cuatro grandes Juegos Panhelénicos. El orden de los libros no ofrece

\footnotetext{
${ }^{1}$ Este trabajo se inscribe dentro del Proyecto de Investigación «Las paremias grecolatinas y su continuidad en las lenguas europeas» (FFI2015-63738-P, Ministerio de Economía y Competitividad de España) y en el marco de los trabajos que lleva a cabo el Grupo de Investigación UCM 930235 Fraseología y paremiología (CEI Campus Moncloa, Clúster de Patrimonio).
} 
ninguna duda, ya que Aristófanes los organizó de acuerdo con la importancia de la competición, de manera que su edición de los poemas pindáricos se abría con las Olimpicas. Más problemática es la cuestión de los criterios que siguió Aristófanes para ordenar los poemas dentro de cada libro, y en concreto por qué eligió (si es que fue elección suya) abrir el libro de las Olimpicas, y por tanto su edición de Píndaro, con la que a partir de entonces llamamos Olimpica primera ${ }^{2}$. Fuese cual fuese la razón, el caso es que desde el siglo II a.C. hasta nuestros días los lectores de Píndaro comenzamos nuestra lectura del poeta con la enigmática frase con la que se abre la primera Olimpica, cuya interpretación ha suscitado muchas discusiones desde la propia Antigüedad: ópı el agua.

Es un comienzo enigmático pero no extraño. Quiero decir que no es extraño que un poeta griego se haga la pregunta de "qué es lo mejor" y nos proponga su respuesta. Por decirlo en palabras del maestro Bruno Gentili ${ }^{3}$, se trata de "il questionario della cultura arcaica ('qual è la cosa più bella' o 'più giusta' o 'migliore' o 'più grande' ecc.), cioè il questionario dei sommi valori”. Las respuestas a esta pregunta son, por supuesto, muy diversas, de acuerdo con el pensamiento de cada poeta y las circunstancias en las que compone su poema. En las elegías con las que Tirteo pretende inflamar de ardor bélico el corazón de los espartanos,

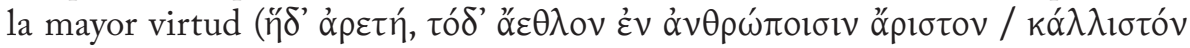
$\tau \varepsilon)^{4}$ es el valor en el combate (fr. 12 West; cf. también fr. 10), por delante del talento para el deporte, la estatura y la belleza física, la riqueza, la realeza o la elocuencia. Por su parte, Teognis (255) asegura que lo más hermoso es la justicia ${ }^{5}$

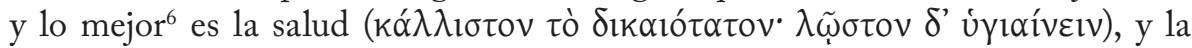
salud es también la primera opción en el celebérrimo escolio ático fr. 890 Page

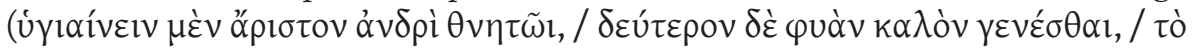

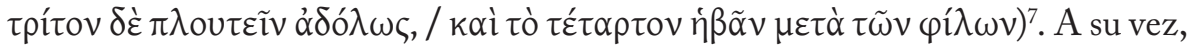
la tercera opción del mencionado escolio, la riqueza, es la primera para Pitermo

${ }^{2}$ Un excelente estudio de la cuestión puede encontrase en Negri 2004. Ya los escolios señalan como causas principales la alabanza de las competiciones de Olimpia con la que se abre la oda (diciéndose que son superiores a las demás), y el hecho de que contenga un extenso relato de uno de los mitos fundacionales de los Juegos.

${ }^{3}$ Gentili 1989: 123-124. Cf. ya Snell 1965: 103.

${ }^{4}$ Ésta es la virtud por excelencia, éste el premio de competición más distinguido / y hermoso que un hombre joven puede ostentar entre sus semejantes (traducción de E. Suárez de la Torre).

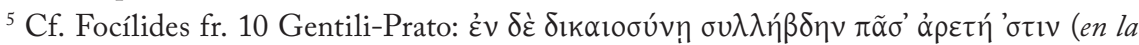

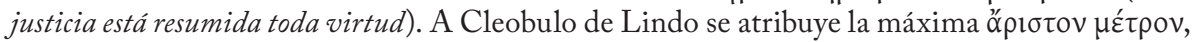
lo mejor es la mesura (cf. Tosi 1993: $\mathrm{n}^{\circ}$ 1760).

${ }^{6}$ Entiendo que la primera elección se refiere al ámbito público y la segunda al ámbito personal.

${ }^{7}$ Tener salud es lo mejor para el hombre mortal, / lo segundo ser de buen natural, / lo tercero ser rico sin fraude, / y lo cuarto gozar de la juventud en compañia de los amigos. 


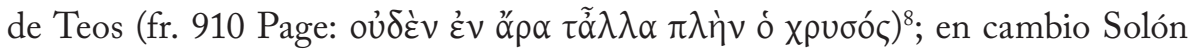
considera que, para los mortales, más importante que la riqueza es la "virtud"

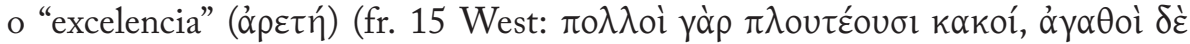

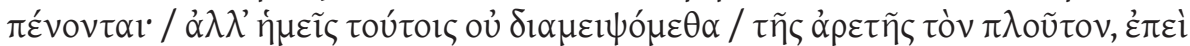

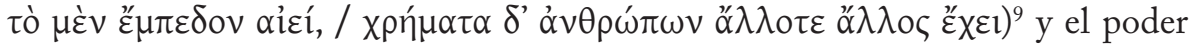
satisfacer las necesidades y los placeres elementales de la vida (la comida, el sexo,

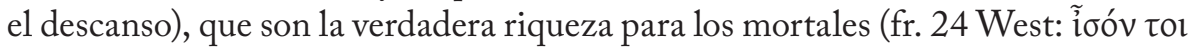

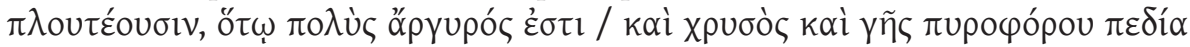

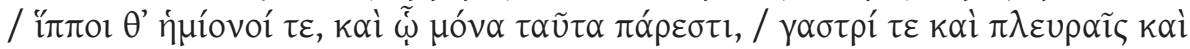

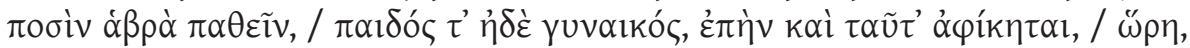

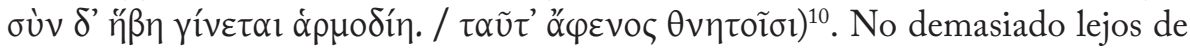
Solón, pero expresándolo más a la manera yámbica, Ananio responde a Pitermo

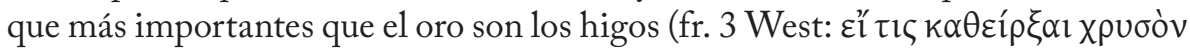

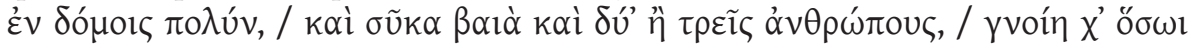

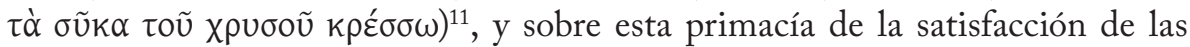
necesidades básicas volveré a propósito del pasaje pindárico que es el centro de atención principal de estas páginas. Las frutas maduras (en este caso no los higos, sino las manzanas y las peras, además de los pepinos) aparecen también en el catálogo de los "valores supremos" que ofrece Praxila de Sición (fr. 747 Page), o mejor dicho, su personaje Adonis cuando es preguntado por las divinidades infernales qué es lo que más lamenta dejar atrás en el mundo de los vivos, ocupando concretamente el tercer lugar, tras la luz del sol y el brillo de las

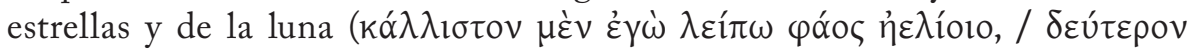

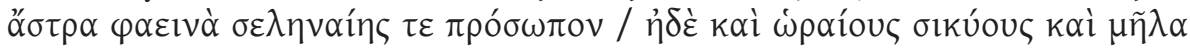

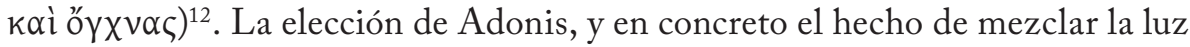
del sol, el brillo de las estrellas y la luna con los pepinos maduros, las manzanas y las peras, debió de parecerles a los griegos signo de la más encantadora ingenuidad o quizá de la más absoluta estupidez, ya que dio lugar al proverbio "ser más ingenuo (o más tonto) que el Adonis de Praxila”, gracias al cual hemos

${ }^{8}$ Ninguna otra cosa vale excepto el oro.

${ }^{9}$ Pues muchos canallas son ricos, mientras que los honrados son pobres, / pero nosotros no intercambiaremos con aquellos / riqueza por virtud, ya que ésta siempre firme se mantiene, I mientras que las riquezas ora un hombre ora el otro las posee (traducción de E. Suárez de la Torre).

${ }^{10}$ Tan rico es el que tiene mucha plata, / oro, campos de tierra rica en trigo, / caballos y mulos, como el que dispone de lo necesario, / gozar de su vientre, sus costados y sus pies, / y de la lozanía de un muchacho y de una mujer, cuando también llega a alcanzar esto, / y le acompaña el adecuado vigor juvenil. / Eso es la riqueza para los mortales... (traducción de E. Suárez de la Torre).

${ }^{11}$ Si alguien encerrara en una casa mucho oro, / unos pocos higos y dos o tres personas, / sabría cuánto mejores que el oro son los higos.

${ }^{12}$ Lo más hermoso que yo abandono es la luz del sol, / lo segundo las estrellas brillantes y la faz de la luna, / y también los pepinos maduros, las manzanas y las peras. 
conservado el fragmento citado en el Corpus Paroemiographorum Graecorum (Collectio Coisliniana 248; Zen. Vulg. 4. 21).

Jenófanes, por su parte, considera que la "sabiduría" (бофía) es el valor supremo, o al menos lo más importante para que una comunidad esté bien

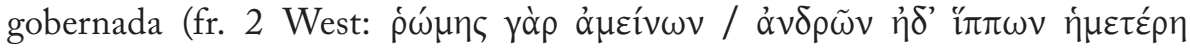
бọín $)^{13}$. Baquílides ${ }^{14}$, más pesimista, hace decir a Heracles (5. 160-162) que para los mortales no haber nacido es lo mejor, y no haber visto el resplandor del sol

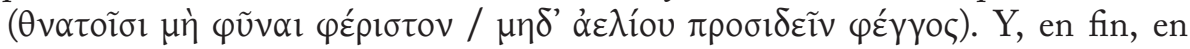
esta serie de variadas soluciones que ofrecen los poetas a la cuestión de qué es lo mejor para los mortales, la respuesta más atrevida y revolucionaria es la que da Safo, para quien "lo mejor" no es un valor objetivo (sea la justicia, la sabiduría, la salud o la luz del sol, los higos, las manzanas o las peras), sino un valor subjetivo:

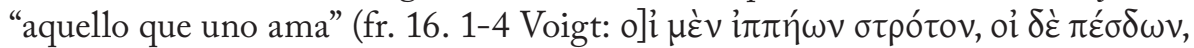

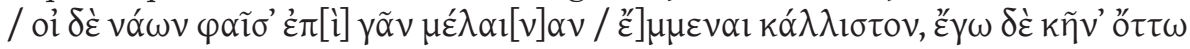

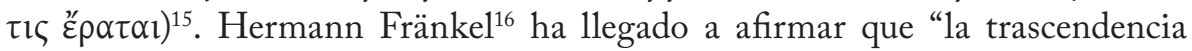
de la asombrosa tesis de Safo fue inmensa", ya que "contenía potencialmente la fuerza necesaria para derribar cualquier valor absoluto...Esto anticipa en parte la tesis del sofista Protágoras según la cual el hombre es la medida de todas las cosas. No es raro que, en esta época, la poesía vaya por delante de la filosofía, preparándole el camino".

Hemos citado aquí una buena cantidad de textos (no de manera ociosa, ya que luego volveremos a referirnos a ellos en nuestra argumentación a propósito del pasaje pindárico que nos ocupa), en los cuales poetas de época arcaica y clásica expresan su opinión sobre "qué es lo mejor". Las respuestas son diversas, pero todas ellas resultan perfectamente comprensibles y a propósito de ninguna de ellas se ha suscitado una controversia ni de lejos comparable con la que ha provocado el comienzo de la Olímpica 1 de Píndaro y en concreto su afirmación inicial de que lo mejor ${ }^{17}$ es el agua:

\footnotetext{
${ }^{13}$ Porque superior a la fuerza de hombres y caballos es nuestra sabiduría.

${ }^{14}$ No obstante, en 9.85 afirma que lo más hermoso es dejar buena fama, que el poeta se encarga de cantar y difundir.

${ }^{15}$ Unos un ejército de jinetes, otros de infantes, otros de naves, dicen que sobre la tierra negra es 10 más hermoso, pero yo, que es aquello que uno ama.

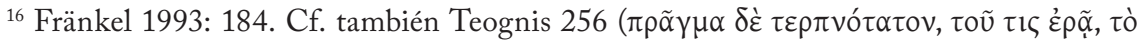

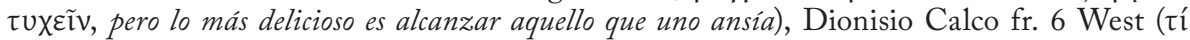

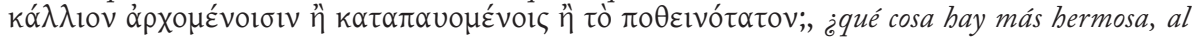
comenzar y al acabar, que lo que más se anhela?) y también la inscripción de Delos citada por

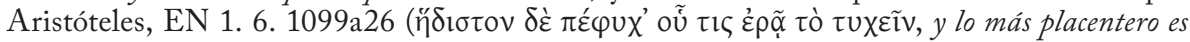
alcanzar lo que uno ansía).

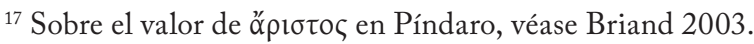




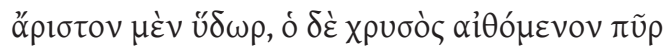

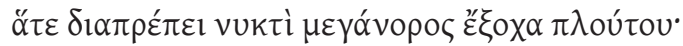

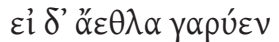

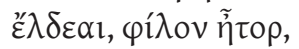

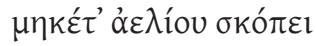

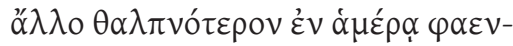

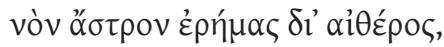

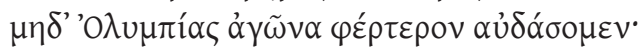

Lo mejor, el agua. Y el oro como fuego incandescente se destaca de noche sobre la soberbia riqueza. Mas si es cantar unos juegos lo que anhelas, corazón mio, no busques ya de día con tu mirada por el cielo desierto un astro esplendoroso más ardiente que el sol, y no podremos hablar de certamen más ilustre que el de Olimpia. [traducción de P. Bádenas y A. Bernabé]

Por qué dice Píndaro que el agua es lo mejor y en qué sentido lo dice, es cuestión debatidísima desde la Antigüedad, a la que se han dado muy diferentes respuestas $^{18}$, que van desde asignar a la expresión un valor absoluto y entender que para Píndaro el agua es lo mejor de todo y en todos los sentidos ${ }^{19}$, hasta interpretar la referencia al agua que inicia el poema en un sentido concretísimo ${ }^{20}$, poniéndose en relación directa bien con la persona del vencedor y las circunstancias de la representación del epinicio (alegándose, por ejemplo, que el palacio de Hierón, donde habría sido representado el epinicio, estaba en la isla de Ortigia, obviamente rodeada de agua, y próximo además a la fuente Aretusa, que se suponía unida con el Alfeo, el río de Olimpia), bien con los protagonistas del relato mítico de la oda (el agua es el reino de Posidón, que desempeña en el

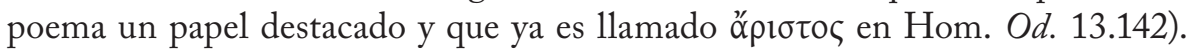
Douglas Gerber considera incluso que todos nuestros esfuerzos por entender el sentido exacto de la máxima están condenados al fracaso, ya que "we shall never know what prompted Pindar's utterance. The most that we can do is adduce passages which illustrate the pre-eminence of water or its use in imagery and say that one or more may have been in Pindar's mind at the time of composition". Yo no soy tan pesimista y creo que sí es posible que alguna o algunas de las interpretaciones propuestas vayan en la dirección correcta, en el sentido de que, aunque puede ser cierto que en la afirmación de Píndaro se acumulen referencias muy diversas, haya alguna o algunas que predominen sobre las demás.

Son tres, a mi juicio, las interpretaciones más dignas de ser tenidas en

${ }^{18}$ Una buena doxografía puede encontrarse en Race 1981, y en Gerber 1982: 7-9.

19 Cf. sobre todo Race 1981: 120-121, que lleva cabo una atinada crítica de esta interpretación.

${ }^{20}$ Las referencias en Gerber 1982: 7-8, y Gentili et alii 2013: 355 ss. . 
cuenta, y entre ellas no incluyo las explicaciones llamémoslas "cabalísticas", que

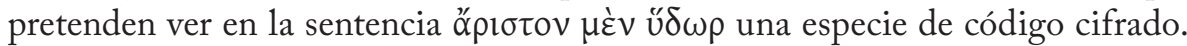
Así, en fecha reciente William Calder ${ }^{21}$ ha sostenido la hipótesis de que ópı

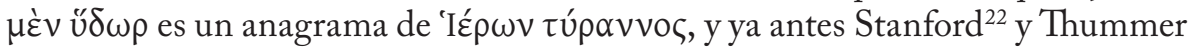
habían hecho notar que quizá sea deliberado el hecho de que esta breve apertura contiene los cinco timbres vocálicos, lo que ha hecho suponer a Slater ${ }^{23}$ que la colocación de la Olímpica 1 al comienzo de la obra de Píndaro no se debe a Aristófanes de Bizancio, sino al propio Píndaro (pero, como por lo demás ya observó Stanford, también los cinco timbres vocálicos se encuentran al comienzo de la

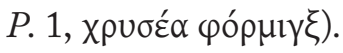

En primer lugar, ya los escolios antiguos a los versos que estamos comentando se hacen eco de una interpretación "cosmológica" de la máxima ơpııбov $\mu \grave{\varepsilon} v$ ű $\delta \omega \rho$, que los escoliastas ponen en relación con la idea de Tales de que el

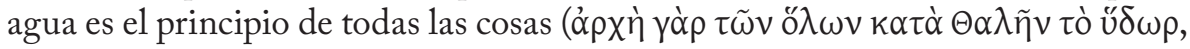
1d) y con el verso homérico (Il. 14. 201) en el que se afirma que el Océano es el

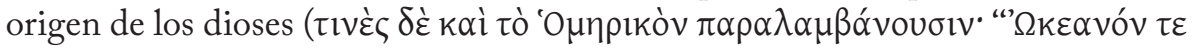

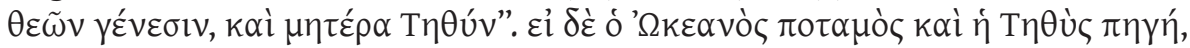

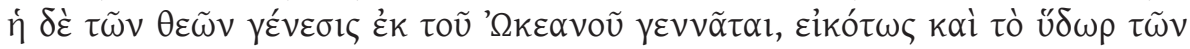

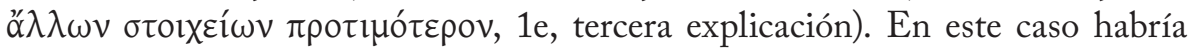

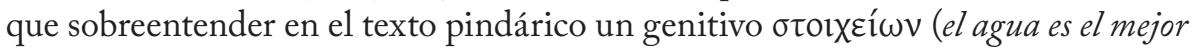
de los elementos) e interpretar que Píndaro estaría diciendo que el agua es el mejor de los cuatro elementos. De hecho, los escolios que transmiten esta interpretación ${ }^{24}$ conceden importancia al hecho de que los elementos tradicionales sean cuatro, igual que son cuatro los grandes Juegos Panhelénicos, de manera que Píndaro estaría diciendo que los Juegos Olímpicos son los mejores entre los cuatro grandes Juegos Panhelénicos como el agua es el mejor entre los cuatro elementos ${ }^{25}$. Esta interpretación cosmológica fue aceptada ya en el primer gran

${ }^{21}$ Calder 2004.

22 Stanford 1967: 83: "it sounds almost as though the master poet was announcing the theme of some great fugue in these sequences of the five main tones of his vowel-scale at the beginning of two major works". Cf. Gerber 1982: 9.

${ }^{23}$ Slater 1986: ad fr. 381. Rechaza tal propuesta, con precisos argumentos, Negri 2004: 19 ss.

${ }^{24}$ La explicación que ofrecen los escolios sobre por qué el agua es el elemento "mejor" y original, viene a coincidir con la que ofrece el erudito Heráclito en sus Alegorías de Homero 22, a la cual se atribuye un origen estoico; cf. Kirk \& Raven 1970: 130 ss.

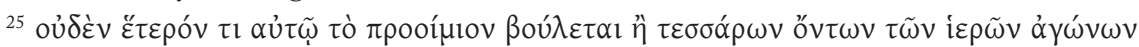

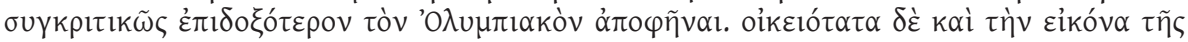

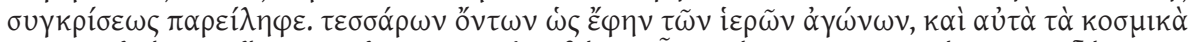

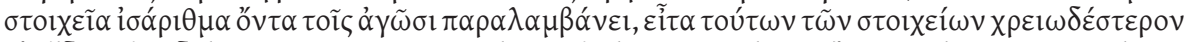

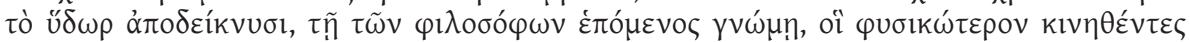

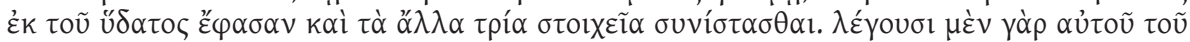

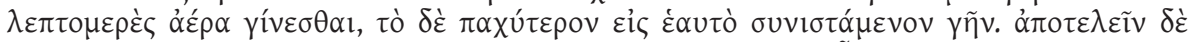

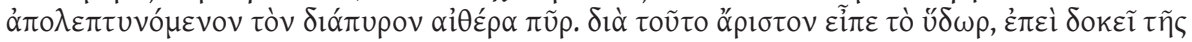


comentario moderno de los epinicios pindáricos (una obra admirable), el que publicó en 1616 Erasmo Schmid ${ }^{26}$ ("ut aqua elementis reliquis; ut aurum metallis reliquis; ut sol stellis reliquis...ita et Olympici ludi reliquis omnibus praestant”), $\mathrm{y}$ ha seguido teniendo luego muchos y sumamente prestigiosos seguidores ${ }^{27}$, como Heyne y Hartung en el XIX, y ya en el siglo XX Rudhardt ${ }^{28}$, Kirkwood ${ }^{29}$, Fernández-Galiano ${ }^{30} \mathrm{o}$ Hermann Fränkel $^{31}$, quien más que en Tales piensa en la influencia de Heráclito sobre Píndaro.

En defensa de la hipótesis de que el poeta esté aludiendo en el pasaje a los elementos primordiales, se ha aducido que en los versos siguientes se habla del fuego y se habla del éter, y el cuarto elemento, la tierra, estaría representado en nuestro pasaje por el oro. Pero, como muy bien señala Race, el oro no es la tierra, y además el fuego y el éter se encuentran en símiles suplementarios, en los que no parece importante el hecho de que sean "elementos". Más aún: si el agua es "el mejor de los elementos", ¿cómo puede Píndaro asegurar a continuación la superioridad del oro?

No podemos saber con seguridad si Píndaro estaba interesado en las especulaciones de los físicos jonios. Pero, en todo caso, como ya advirtió Boeckh ${ }^{32}$, no creo que debamos llevar estas hipótesis al extremo de convertir a Píndaro en un

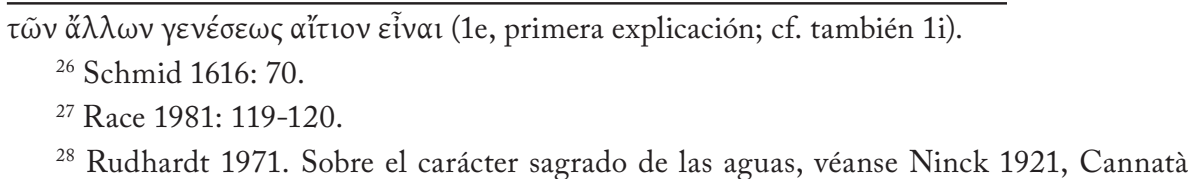
Fera 2012, y Costa, Palahí \& Vivó 2012.

${ }^{29}$ Kirkwood 1982: 48.

${ }^{30}$ Fernández-Galiano 1956: 103 y 107. Cf. también Bádenas de la Peña P. \& Bernabé Pajares, A. (2002), Pindaro. Epinicios. Madrid: 40.

31 "A thought pattern in Heraclitus", AJP 59, 1938, recogido en Fränkel 1993: 438-439: "como ocurre varias veces en Píndaro, hay en el fondo ideas de Heráclito. Según Heráclito, el agua es el elemento de la vida vegetativa frente a la tierra muerta y pasiva, y el fuego es el elemento de la vida superior, frente a la tierra y el agua. Además, Heráclito comparó, como Píndaro, el oro, en tanto que compendio de los valores materiales, con el fuego, en tanto que medida metafísica del valor (fr. 90). En tercer lugar, otro aforismo característico de Heráclito (fr. 99) constituye el modelo para otra pareja de opuestos en Píndaro. El 'fuego' en la noche representa la luz frente a la oscuridad. Pero el sol en el día, 'en el éter solitario', es la única luz existente frente a todos los fuegos menores del cielo; ningún astro puede ser visto cuando brilla el sol. El comienzo del poema pretende, pues, inculcar el concepto de un valor sobresaliente mediante ejemplos tomados de diferentes campos, para situar la victoria que se celebra en esa ocasión en la clase de los máximos valores".

${ }^{32}$ Boeckh 1811: 103: "mihi tamen hoc veteris poetae simplicitati parum convenire videtur: neque isti explicationi e philosophorum vel poetarum physicorum disciplina petitae auri addita mentio favet. Reducamus potius sensum ieiuniorem, genuina communis vitae sapientia at antiquitatis auctoritate commendabilem; quippe ut inter alia Schol. monet, aqua optima habetur, quod sine ea vivi non potest: quod accuratius Aristoteles expressit, ob usum frequentissimum aquam praestantissimam dici tradens Rhet. I, 7”. 
filósofo (por más que, como señala Hermann Fränkel, en esta época la poesía vaya "por delante de la filosofía, preparándole el camino"). Y también creo (pero tal vez me equivoque) que tales especulaciones cosmológicas están fuera de lugar en la introducción de una oda que celebra una victoria olímpica de Hierón de Siracusa en la carrera de caballos.

Pero si bien (creo yo) hemos de considerar a Píndaro en primer lugar desde su condición no de filósofo, sino de poeta que compone por encargo un poema para celebrar una victoria concreta de un individuo concreto en un contexto concreto, tampoco debemos, en mi opinión, pretender explicar el sentido de la máxima

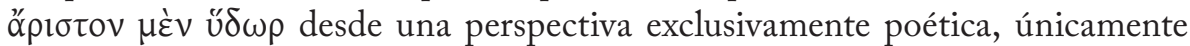
como una alusión al valor y a la función de la canción del poeta en la celebración de la victoria deportiva. Me explico.

Aunque ya contaba con antecedentes en el libro de Finley Píndaro y Esquilo ${ }^{33}$ o en The Pindaric mind de Thomas Hubbard ${ }^{34}$, la hipótesis de que la expresión inicial de la Olimpica 1 debe entenderse principalmente en clave "poética" (o, por utilizar una expresión de moda, pero que a mí personalmente no me gusta, en clave "poetológica") $)^{35}$, ha sido defendida con especial vigor y precisión por Eveline Krummen en su conocido libro Pyrsos Hymnon. Actualidad festiva y tradición mítico-ritual en Pindaro ${ }^{36}$.

Krummen parte del hecho (indudable y bien conocido) de que en Píndaro el agua y el oro son imágenes que se asocian con frecuencia con la poesía, y en concreto con el canto del poeta como elemento indispensable para que la gloria de la victoria y del vencedor sea adecuadamente alabada y difundida ${ }^{37}$. Así, en

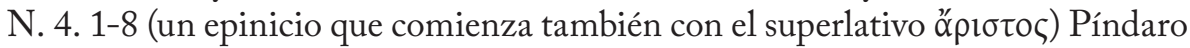
afirma que el elogio del poeta es como el agua caliente que relaja los músculos del atleta después de la competición:

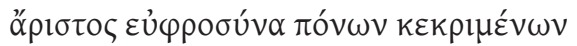

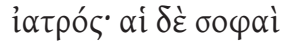

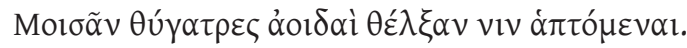

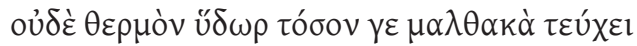

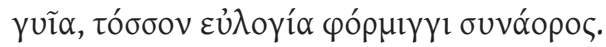

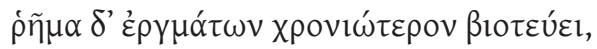

\footnotetext{
${ }^{33}$ Finley 1955: 52-53.
}

${ }^{34}$ Hubbard 1985: 154-155, y también en 14-15, a propósito de O. 3. 42-45: "en ambos pasajes el agua puede evocar el valor refrescante, la fluidez nutritiva del discurso poético, mientras que el oro incorpora la espléndida beneficencia y la generosidad del vencedor que ha encargado el poema”.

35 Cf. Nünlist 1998, que apoya la interpretación de Krummen en p.172, n.18.

${ }^{36}$ Krummen 1990: 211-216.

${ }^{37}$ Véanse también Kirkwood 1982: 48; Gerber 1982: 8. 


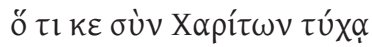

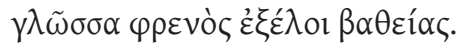

El mejor sanador de las fatigas, después que han hecho crisis, es el gozo. Las canciones, sabias hijas de las Musas, las alivian con la imposición de sus manos. Y es que a los músculos no los relaja tanto el agua tibia como el elogio acompañado de la forminge, y más perdurable que las hazañas es la vida de las palabras que, con ayuda de las Gracias, hace salir la lengua de lo hondo del espiritu

[traducción de P. Bádenas y A. Bernabé].

Y en N. 7. 61-63 el merecido canto de elogio es como una corriente de agua que el poeta trae al vencedor ${ }^{38}$ :

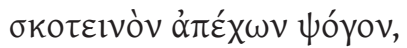

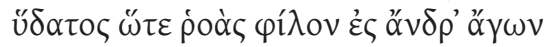

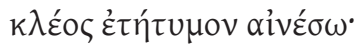

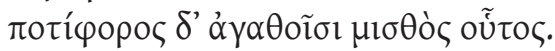
Apartando la sombría maledicencia, procuraré a un amigo, como si un caudal de agua le llevara, el auténtico elogio de su gloria. Tal es la recompensa adecuada a los hombres de bien [traducción de P. Bádenas y A. Bernabé].

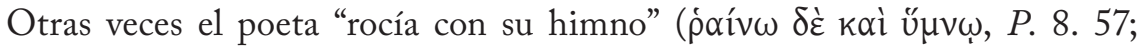
cf. también P. 5.98 ss.) o "cura la sed de cantos" del vencedor ( $\varepsilon \mu \varepsilon \dot{~} \delta$ ” oũv $\tau 1 \varsigma$

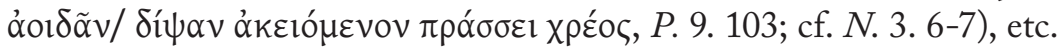

$\mathrm{E}$ igualmente, como muy bien señala Krummen, también el oro aparece frecuentemente ligado al brillo de la victoria (en 0.8 . 1 Olimpia es invocada

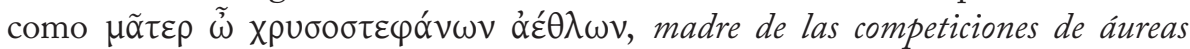
coronas) y, como consecuencia, al canto del poeta ${ }^{39}$, y en el epinicio "luz" es asímismo metáfora para el canto que evita que la gloria del vencedor caiga en la noche del olvido; de manera que podría ser cierto que "los conceptos Agua, Oro, Fuego en la Noche, resultan ser una clara referencia a la situación básica: la victoria, el vencedor".

Es indudable, en efecto, que la imagen del agua y también la imagen del oro están frecuentemente ligadas a la poesía en la obra de Píndaro. Pero creo que en nuestro caso lo estarían por alusión y no por referencia directa. Quiero decir que es posible que al público que escuchó en Siracusa el comienzo de la Olímpica 1 las referencias al agua y al oro pudieran evocarle de alguna manera la poesía, pero no hasta el punto de que si el coro decía, al comienzo del poema, "lo mejor

38 "La imagen concretiza un aspecto esencial del canto, que alimenta la fama, como a un árbol el riego. Otras veces, el canto es la 'bebida', el 'baño' que restaura las fuerzas del luchador, el 'ensalmo' que calma el dolor del esfuerzo” (Lasso de la Vega 1977: 104).

${ }^{39}$ Cf. Segal 1964, y Duchemin 1952 = 1970: 278-279. 
es el agua", los oyentes entendieran automáticamente "lo mejor es el canto del poeta que elogia al vencedor" (“'si uno ha vencido, entonces lo mejor es el agua', la regeneración física y finalmente también psíquica, conseguida a través de la alabanza", dice textualmente Krummen ${ }^{40}$ ), por mucho que ese público estuviera familiarizado con el arte de Píndaro, lo que quizá no fuera el caso de muchos de los siracusanos presentes durante la primera representación del epinicio. En los textos que Krummen y otros citan en apoyo de esta interpretación, el contexto hace evidente la relación directa entre el agua y la poesía; en nuestro contexto, en cambio, a mí me parece sumamente difícil que el público estableciera tal identificación; demostraría una perspicacia inaudita en el auditorio (o quizá es que pienso que yo sería incapaz de captar semejante sutileza y por eso niego a los demás la posibilidad de hacerlo).

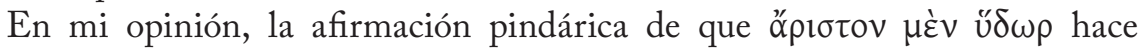
referencia, en primer lugar y sobre todo, a un hecho más evidente y sencillo ${ }^{41}$ : la constatación de la necesidad fundamental del agua para la vida de cualquier ser, y para la vida del hombre en concreto. Los escolios antiguos ya apuntan esta

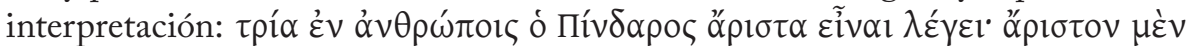

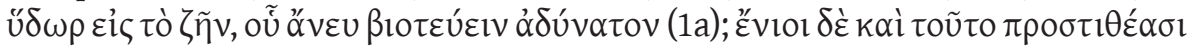

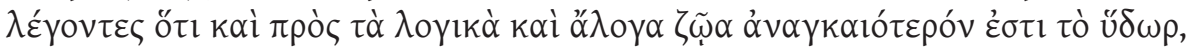

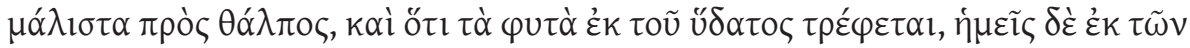

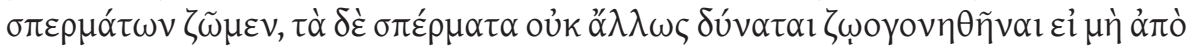

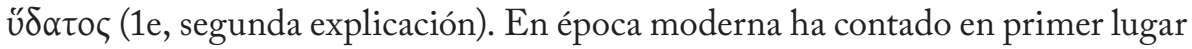
con la defensa autorizada de Boeckh ("reducamus potius sensum ieiuniorem, genuina communis vitae sapientia at antiquitatis auctoritate commendabilem; quippe ut inter alia Schol. monet, aqua optima habetur, quod sine ea vivi non potest"), quien cita diversos pasajes de autores griegos y latinos que aseguran la absoluta necesidad del agua para la vida humana. Y luego esta interpretación ha convencido también a Gildersleeve" ("no profound philosophical tenet is involved...The poet enphasizes, after the Greek fashion, water as the source

40 "'Wenn einer gesiegt hat, dann ist in dieser Situation das unmittelbar beste Wasser', die physische und schliesslich auch psychische Regeneration, letztere durch das Lob" (Krummen 1990: 212). Rechaza esta posibilidad Gerber 1982: 8.

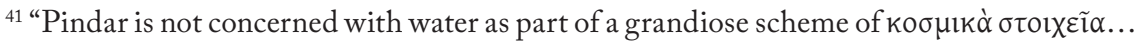
or as the best single thing in the universe" (Race 1981: 121-122).

42 Gildersleeve 1890: 129. Wilamowitz (1966: 491) comenta al respecto: "Natürlich ist das Wasser das Nützlichste, denn der Grieche kennt deine durstigen Berge und Äcker und verehrt jede Quelle und jeden Bach. Aber das reicht hier nicht, denn das Gold, das

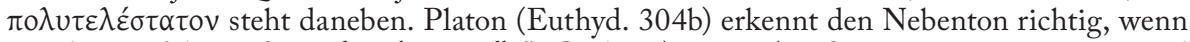

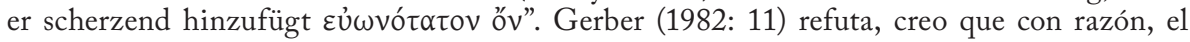
argumento de Wilamowitz: "Wilamowitz feels that Pindar attaches more significance to gold than to water...Pindar, however, says nothing about the cheapness of water and the form of the priamel does not allow us to assign less weight to any one component. Pindar is in no sense comparing water to gold". 
and sustenance of life"), Puech ${ }^{43}$ o Verdenius ${ }^{44}$, o Gentili et alii, entre otros. $Y$ ha sido defendida con especial insistencia y, creo yo, con especial acierto, por William Race ${ }^{45}$. Race parte del estudio de diversos pasajes pindáricos en los que la referencia a las necesidades vitales básicas del hombre sirve de "contraste" (foil) para enfatizar el valor del éxito deportivo cantado por el poeta, hasta el punto de constituir un "patrón del pensamiento de Píndaro". Dos son los textos más ilustrativos al respecto:

1) En O. 11 Píndaro inicia su elogio de la victoria del niño boxeador Hagesidamo de Locros con las palabras:

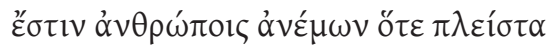

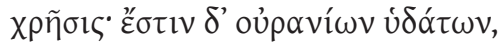

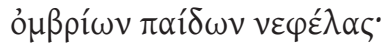

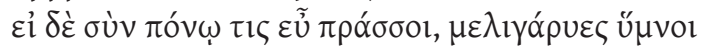

$\dot{v} \sigma \tau \varepsilon \dot{\varepsilon} \rho \omega v \dot{\alpha} \rho x \dot{\alpha} \lambda o ́ \gamma \omega v$

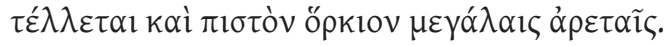

Momentos hay en que los hombres tienen la máxima necesidad de brisas, otros hay en que de aguas del cielo, húmedas hijas de la nube. Pero si con su esfuerzo alguien logra triunfar, los dulcísonos himnos constituyen el principio de futuras alabanzas y testimonio fiel de las grandes hazañas [traducción de P. Bádenas y A. Bernabé].

Píndaro habla explícitamente de la "necesidad" o "utilidad" de los vientos y del agua de la lluvia ( $\chi \rho \tilde{\eta} \sigma ı \varsigma$, v. 2), el mismo término que emplea Aristóteles en $R h$ 1. 7. 1364a26 ss., cuando cita ópı la referencia a estas "necesidades básicas" del hombre se pasa a la victoria y a su celebración a través de la canción, empleándose además una estructura sintáctica muy similar ( $\varepsilon \grave{i} \delta \dot{\varepsilon} . . .$, en 0.11 .4 y 0.1 .3 ).

2) En I. 1. 47-51 la gloria conseguida por el tebano Heródoto en la carrera y su celebración, es enfatizada mediante una nueva alusión a las necesidades básicas del hombre, la comida en este caso:

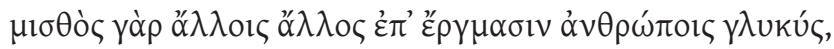
$\mu \eta \lambda$

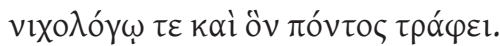

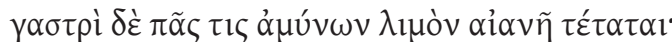

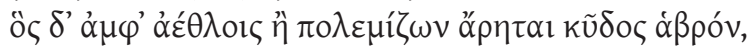

\footnotetext{
${ }^{43}$ Puech 1958: 26 n.1.

${ }^{44}$ Verdenius 1987: 35.

${ }^{45}$ Aceptan la interpretación de Race, aunque con precisiones, Uchida 1986 y Lehnus 1983.
} 


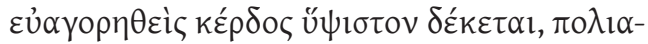

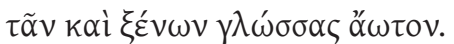

Pues cada hombre recibe una dulce compensación por sus trabajos: el pastor, el labriego, el pajarero y aquel a quien la mar da su sustento; todo el mundo se esfuerza por defender su vientre del hambre lacerante, pero el que en los juegos o como combatiente se alza con espléndida gloria, obtiene con el encomio la más excelsa ganancia, quintaesencia de la lengua de compatriotas y extranjeros [traducción de P. Bádenas y A. Bernabé].

Esta interpretación no sólo concuerda, como acabamos de apreciar, con lo que el propio Píndaro afirma en otros pasajes de sus epinicios, sino que además se adecúa perfectamente a las respuestas que otros poetas anteriores o contemporáneos dan a la pregunta "qué es lo mejor". Como pudimos comprobar al comienzo de nuestro trabajo, los poetas de época arcaica o clásica, cuando se preguntan qué es lo más importante para la vida humana, no suelen responder con especulaciones cosmológicas o (mirándose el ombligo) con profundas reflexiones sobre el valor de la poesía, sino que ofrecen respuestas claras y precisas, y nos dicen, si consideran la cuestión desde la perspectiva social, que lo mejor para una comunidad es el valor de sus miembros en el combate, o la justicia, o la virtud, o la sabiduría; y, si consideran la cuestión desde el punto de vista individual, responden que lo mejor para el hombre mortal es la salud, o el dinero, o lo que uno ama, o la luz del sol, o la comida y el sexo, o los higos, los pepinos maduros, las manzanas y las peras. En este conjunto de respuestas, creo yo que encajaría perfectamente que la respuesta de Píndaro fuera que "lo mejor es el agua", considerándola como elemento esencial para la supervivencia. Es posible, además, que "lo mejor es el agua" fuera incluso una expresión proverbial o, al menos, tópica ${ }^{46}$, aunque no podemos saber si lo era antes de Píndaro o se hizo proverbial precisamente a partir del poeta tebano (Gottfried Hermann consideraba que era "eine dem Pindar eigne Sentenz"). Platón (Euthd. 304b) cita la expresión mencionando explícitamente el nombre de Píndaro; por su parte, Aristóteles (Rh. 1. 7. 1364a26 ss.) introduce su cita con una fórmula habitual para introducir expresiones proverbiales $(\lambda \varepsilon ́ \gamma \varepsilon \tau \alpha$, se dice) y sin mencionar a Píndaro, pero eso no significa necesariamente que no esté pensando en el pasaje pindárico en concreto. Kirkwood sugiere que pudiera ser un indicio del carácter proverbial de la expresión el hecho de que "las dos formulaciones de Píndaro [O. 1.1 y 0.3. 42] sean prácticamente

${ }^{46}$ Véase Gerber 1982: 9 (citando los pasajes de Platón y Aristóteles, y también a Plu. Aquane an ignis utilior 955d; Ath. 2. 40f; AP 9. 629; 9. 809; 11. 370), y Race 1981: 121, citando a Dissen (Pindari Carmina II, Göttingen 1830: 5) y Farnell (1932: 4). Cf. también

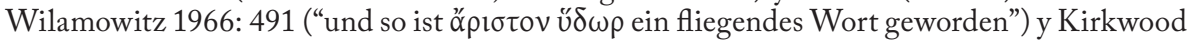
1982: 48. 
idénticas" ${ }^{\prime 77}$. En todo caso, la expresión se extendió ligada al nombre de Píndaro ${ }^{48}$.

A partir de esta interpretación de ópı sobre todo al agua como necesidad humana básica, creo que se explica muy bien la secuencia de ideas del proemio de la Olímpica 1 (y también de 0.3 . 42-45), tal como hace Race siguiendo una sugerencia de Gildersleeve (anticipada por Boeckh) y, en última instancia, siguiendo la glosa del escolio 1a. Entiendo, en efecto, que la secuencia "agua - oro - competiciones de Olimpia" que desarrolla el proemio de la Olímpica 1, debe interpretarse como una gradación que va de lo

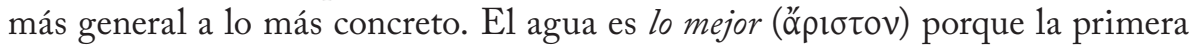
necesidad del hombre es sobrevivir ( $\tau$ '̀ $\zeta \tilde{\eta} v$ dice el escolio) y la supervivencia del hombre está ligada al agua, conditio sine qua non de nuestra existencia. Pero, naturalmente, en el mundo de valores que refleja el epinicio el simple hecho de sobrevivir "físicamente" no es suficiente; como más de un siglo después dirá Aristóteles (Pol. 3. 9. 6. 1280a), no se trata de vivir, sino de vivir bien. Y para eso está la riqueza (y el oro, que es su expresión máxima), que contribuye a hacer la vida más valiosa. Pero no basta tampoco con ser rico: hay que hacer buen uso de esa riqueza ${ }^{49}$, por ejemplo, participando en las competiciones de Olimpia; es éste un motivo recurrente en el epinicio: la victoria deportiva procura la más alta gloria, la cual el poeta difunde con su canto y la hace inmortal. Sólo así es posible conseguir las dos máximas aspiraciones que puede tener un hombre (en el mundo de valores que refleja el epinicio): ser admirado en vida y recordado y alabado tras su muerte ${ }^{50}$. En definitiva, en el proemio se nos estaría diciendo que el agua permite vivir; la riqueza vivir bien (y el oro, que representa la máxima riqueza, vivir muy bien); y la victoria deportiva alcanzar la gloria (y si esa victoria es en Olimpia, alcanzar la máxima gloria).

Esta interpretación para el proemio de la $O .1$ es en cierto modo comparable a la interpretación que creo debe darse, como ya defendí hace 30 años, a propósito de un texto controvertido de Baquílides, que se ha puesto frecuentemente en relación con nuestro pasaje e incluso se ha dicho que es un eco o imitación de Píndaro. Al final del epinicio tercero, que celebra también una victoria olímpica de Hierón, Baquílides afirma lo siguiente (vv. 85 ss.):

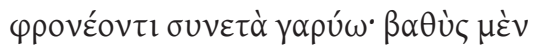

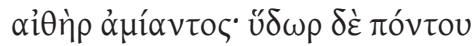

${ }^{47}$ Sobre O. 3. 42-45 como "autocita" de O. 1.1 ss., véanse Gerber 1982: 5-6; Verdenius 1987: 35; Clay 2001.

${ }^{48}$ Se trata, en efecto, del verso pindárico más citado por los antiguos. Cf. Farnell 1932: 4, Fernández-Galiano 1956: 107, Cannatà Fera 2012, Gentili et alii 2013: 355.

${ }^{49}$ Cf. Medda 1987.

${ }^{50}$ Aunque la cita es de Claudio Eliano (NA 1. 6), creo que refleja bien el pensamiento pindárico (cf., por ejemplo, I. 5.12 ss.). 


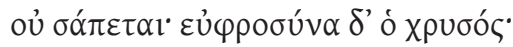

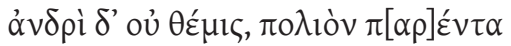

$\gamma \tilde{\eta} \rho \alpha \varsigma, \theta \alpha \dot{\lambda}[\varepsilon l \alpha] v \propto \tilde{v} \tau \iota \varsigma \alpha \dot{\alpha} \gamma \kappa о \mu i ́ \sigma \sigma \alpha l$

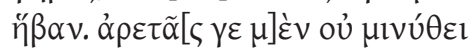

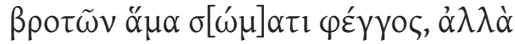

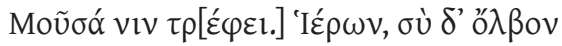

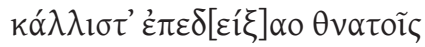

$\ddot{\alpha} v \theta \varepsilon \alpha \ldots . . .$.

Pronuncio palabras comprensibles para los sensatos: el profundo éter es inmaculado, y el agua del mar no se pudre; y una alegría es el oro, pero al hombre no le es lícito abandonar la cana vejez y de nuevo recobrar la florida juventud. Sin embargo, de la virtud no disminuye el brillo a la vez que el cuerpo de los mortales, sino que la Musa la nutre. Hierón, tú de la dicha las más hermosas flores has mostrado a los mortales...

Hay, por supuesto, notables diferencias entre el priamel de Píndaro y el de Baquílides (precisamente en la referencia inicial al agua y al éter), pero la idea general creo que es comparable, especialmente en lo que se refiere a la expresión

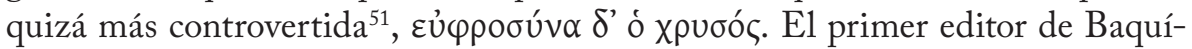
lides, Kenyon, interpretaba el oro como un "elemento eterno", al mismo nivel

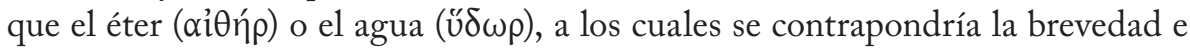
incertidumbre de la vida humana (vv. 88 ss.); Kenyon traduce, en consecuencia, "gold is a joy for ever". Esta fue la interpretación más habitual entre los primeros estudiosos del pasaje (Jebb, Taccone, Wilamowitz, Jurenka, Festa, etc.). Sin embargo, a mí me parece difícil de admitir, en primer lugar porque "for ever" no lo dice, al menos explícitamente, el texto griego, y en segundo lugar porque, si el oro fuera concebido en el pasaje como un "elemento eterno", esperaríamos que se dijera de él algo similar a lo que se dice del éter o del agua: que es "inmaculado" o "que no se pudre". Pero lo que Baquílides dice de él es que es "una alegría", ¿y acaso la alegría es eterna e inmutable para los mortales? No es un pensamiento precisamente muy griego. Por eso, intérpretes más recientes como Christopher Carey o Herwig Maehler ${ }^{52}$ opinan que Baquílides hace referencia al oro en su aspecto más material: el oro es la riqueza, pero entendida aquí en sentido negativo, como un bien pasajero (igual que la juventud, citada inmedia-

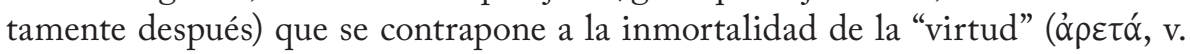

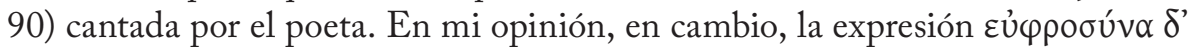
ó xpuøós debe interpretarse de otra manera en el contexto del pasaje, y de una manera que acerca estos versos a los pindáricos que nos ocupan. A mi entender,

\footnotetext{
${ }^{51}$ Brannan 1973: 211 ss.; García Romero 1987: 173 ss.

${ }^{52}$ Maehler 1982: ad loc.; Carey 1977-1978: 69-71.
} 
el oro (la riqueza) no tiene valor negativo en el epinicio, y menos aún puede tenerlo en un epinicio en el que se alaba continuamente la liberalidad de Hierón

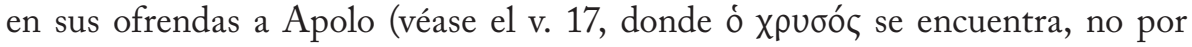
casualidad, en posición tautométrica con respecto al v. 87) y en su celebración del triunfo. En mi opinión, aquí el oro está entendido en su aspecto material, pero no con valor negativo (como elemento perecedero que contrasta con la eternidad de la gloria), sino con valor positivo, como un medio de conseguir la inmortalidad. La secuencia de pensamiento sería, entonces, la siguiente: "el éter y el mar siempre existen; y el oro es motivo de alegría, ya que, pues la vida del hombre es perecedera, permite conseguir gloria y hacer que ésta sea inmortal por medio de la canción del poeta”. El oro en el pasaje no tendría carácter negativo, sino positivo, y permitiría la transición desde los elementos imperecederos a la única eternidad accesible para el hombre, la inmortalidad de la fama a través del canto.

En definitiva, en mi opinión, en la afirmación pindárica de que "lo mejor es el agua" debemos ver ante todo una referencia al agua como necesidad humana básica y como elemento imprescindible para la vida. Secundariamente, es posible que al oyente o lector de Píndaro la presencia del agua y del oro pudiera sugerirle la imagen de la poesía. E incluso podemos pensar que en realidad Píndaro no está tan lejos de los físicos jonios, y de Tales de Mileto en particular, porque (utilizando palabras de Alberto Bernabé) ${ }^{53}$, "otros trataron de explicar el postulado del milesio como consecuencia de una observación racional del comportamiento de las cosas. Así se supuso que el filósofo habría reparado en las variadas formas que toma el agua en la naturaleza..., lo que pudo hacerle concebir la idea de que el agua era el elemento más adecuado para transformarse en los demás ${ }^{54}$. Probablemente más cerca de la realidad estaba Aristóteles [Metafísica 983b] cuando cree que el motivo más poderoso que impulsó al filósofo a considerar el agua como elemento primordial es la íntima relación de este elemento con la vida, su carácter vivificador de la naturaleza toda".

\section{Bibliografía}

Bernabé Pajares, A. (1987), De Tales a Demócrito. Fragmentos presocráticos. Madrid. Boeckh, A. (1811), Pindari opera quae supersunt. Leipzig.

Brannan, R. (1973), "Bacchylides'Third Ode”, CF 27: 187-229.

${ }^{53}$ Bernabé Pajares 1987: 44. Cf. también Onians 1951: 229 ss.

${ }^{54}$ Esta explicación se encuentra también en los escolios a Píndaro (1e, primera explicación), aunque igualmente esos mismos escolios emplean, de manera significativa, la expresión "el más necesario de los elementos" ( $\tau \tilde{\omega} \nu \sigma \tau o l \chi \varepsilon i ́ \omega \nu ~ \chi \rho \varepsilon \imath \omega \delta \varepsilon ́ \sigma \tau \varepsilon \rho \circ \nu)$ para referirse al agua. 
Briand, M. (2003), "Le vocabulaire de l'excellence chez Pindar”, $R P h$ 77: 203-218.

Calder, W. (2004), “An early anagram?: Pindar O1.1”, en S.M. Bay (ed.), Studia paleophilologica Professoris G.M. Browne in honorem oblata. Champaign (Illinois), 45.

Cannatà Fera, M. (2012), "Acqua e poesia nella Grecia antica”, en A. Calderone (ed.), Cultura e religione delle acque. Roma, 3-16.

Carey, Ch. (1977-1978), “Bacchylides 3.85-90”, Maia 28-29: 69-71.

Clay,J.S. (2001), “Olympians 1-3: A song cycle?”, en L. Athanassaki \& E. Bowie (eds.), Archaic and classic choral songs: Performance, Politics and Dissemination. Berlin-Boston, 337-345.

Costa, A., Palahí, L. \& Vivó, D. (eds.) (2012), Aquae Sacrae. Agua y sacralidad en la Antigüedad. Gerona.

Duchemin, J. (1952), "Essai sur le symbolisme pindarique. Or, lumière et couleurs", REG 65: 46-58 (recogido en W.M. Calder III \&J. Stern [eds.] [1970], Pindaros und Bacchylides. Darmstadt, 278-289).

Farnell, L.R. (1932), Critical commentary to the works of Pindar. London [reimpr. Amsterdam 1961].

Fernández-Galiano, M. (1956), Pindaro. Olimpicas. Madrid.

Finley, J.H. (1955), Pindar and Aeschylus. Cambridge (Mass.).

Fränkel, H. (1993), Poesía y filosofía de la Grecia arcaica. Trad. española, Madrid.

García Romero, F. (1987), Estructura de la oda baquilidea: estudio composicional y métrico. Madrid.

Gentili, B. (1989), Poesia e pubblico nella Grecia antica. Bari.

Gentili, B., Catenacci, C., Giannini, P. \& Lomiento L. (2013), Pindaro. Le Olimpiche. Milano.

Gerber, D.E. (1982), Pindar's Olympian 1. A commentary. Toronto-BuffaloLondon.

Gildersleeve, B.L. (1890), Pindar. The Olympian and Pythian Odes. New York (reimpr. Amsterdam 1965).

Hubbard, Th.K. (1985), The Pindaric mind. Leiden.

Kirk, G.S. \& Raven, J.E. (1970), Los filósofos presocráticos. Trad. española, Madrid.

Kirkwood, G. (1982), Selections from Pindar. Chico (California).

Krummen, E. (1990), Pyrsos Hymnon. Festliche Gegenwart und mythisch-rituelle Tradition im Pindar. Berlin.

Lasso de la Vega, J. (1977), "La Séptima Nemea y la unidad de la oda pindárica”, EClás 79: 59-139. 
Lehnus, L. (1983), "Problemi della tradizione filologica”, en R. Copioli (ed.), Tradurre poesia. Brescia, 107-110.

Maehler, H. (1982), Die Lieder des Bakchylides. Leiden.

Medda, E. (1987), "La lode della ricchezza negli Epinici di Pindaro", SCO 37: 109-131.

Negri, M. (2004), Pindaro ad Alessandria. Brescia.

Ninck, M. (1921), Die Bedeutung des Wasser im Kult und Leben der Athen. Leipzig.

Nünlist, R. (1998), Poetologische Bildersprache in der frühgriechischen Dichtung. Stuttgart-Leipzig.

Onians, R.B. (1951), The origins of European thought about the Body, the Mind, the Soul, the World, Time and Fate. Cambridge.

Puech, A. (1958), Pindar. Olympiques. Paris.

Race, W.H. (1981), "Pindar's 'Best is water': Best of what?”, GRBS 22: 119-124.

Rudhart, J. (1971), La thème de l'eau primordial dans la mythologie grecque. Bern.

Rueda González, C. (2000), Referencias al quehacer poético en la lírica griega arcaica. Tesis Univ. Complutense, Madrid.

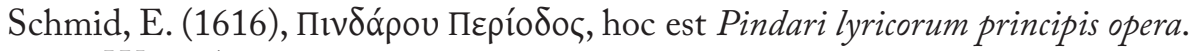
Wittenberg.

Segal, Ch. (1964), "Gold and man in Pindar's First and Third Olympian Odes", HSCPh 68: 211-267.

Slater, W.J. (1986), Aristophanis Byzantii Fragmenta. Berlin.

Snell, B. (1965), Dichtung und Gesellschaft. Hamburg.

Stanford, W.B. (1967), The sound of Greek. Berkeley-London.

Tosi, R. (1993, 8a ed.), Dizionario delle sentenze latine e greche. Milano.

Uchida, T. (1986), "Die Gestalt des Dichter in Pindars erster olympischer Ode”, AundA 32: 1-19.

Verdenius, W.J. (1987), Commentaries on Pindar I. Leiden.

von Wilamowitz-Moellendorff, U. (1966, 2ª ed.), Pindaros. Berlin-ZürichDublin. 